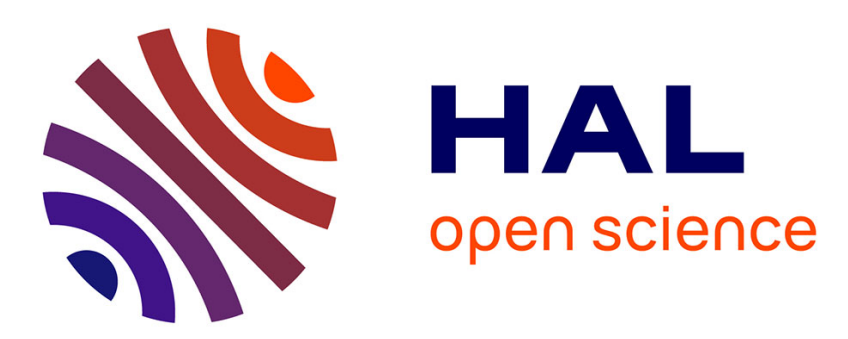

\title{
The Role of Data Analytics in Startup Companies: Exploring Challenges and Barriers
}

Ilias O. Pappas, Letizia Jaccheri, Vebjørn Berg, Jørgen Birkeland

\section{To cite this version:}

Ilias O. Pappas, Letizia Jaccheri, Vebjørn Berg, Jørgen Birkeland. The Role of Data Analytics in Startup Companies: Exploring Challenges and Barriers. 17th Conference on e-Business, e-Services and e-Society (I3E), Oct 2018, Kuwait City, Kuwait. pp.205-216, 10.1007/978-3-030-02131-3_19 . hal-02274164

\section{HAL Id: hal-02274164 \\ https://hal.inria.fr/hal-02274164}

Submitted on 29 Aug 2019

HAL is a multi-disciplinary open access archive for the deposit and dissemination of scientific research documents, whether they are published or not. The documents may come from teaching and research institutions in France or abroad, or from public or private research centers.
L'archive ouverte pluridisciplinaire HAL, est destinée au dépôt et à la diffusion de documents scientifiques de niveau recherche, publiés ou non, émanant des établissements d'enseignement et de recherche français ou étrangers, des laboratoires publics ou privés.

\section{(c)(1)}

Distributed under a Creative Commons Attribution| 4.0 International License 


\title{
The Role of Data Analytics in Startup Companies: Exploring Challenges and Barriers
}

\author{
Vebjørn Berg ${ }^{[0000-0001-5611-964 X]}$, Jørgen Birkeland ${ }^{[0000-0003-3444-4075]}$, \\ Ilias O. Pappas ${ }^{[0000-0001-7528-3488]}$, and Letizia Jaccheri ${ }^{[0000-0002-5547-2270]}$ \\ Department of Computer Science, Norwegian University of Science and Technology, \\ Sem Sælandsvei 9, 7491 Trondheim, Norway \\ vebjorbe@stud.ntnu.no jorgebi@stud.ntnu.no \\ ilpappas@ntnu.no letizia.jaccheri@ntnu.no
}

\begin{abstract}
The advancement in technology is transforming societies into digital arenas and paves the way towards the achievement of digital transformation. With every transaction in the digital world leading to the generation of data, big data and their analytics have received major attention in various fields and different contexts, examining how they may benefit the different actors in the society. The present study aims to identify how startups that develop products with both software and hardware parts can generate value from data analytics and what challenges they face towards this direction. To this end, we performed a multiple-case study with early-stage startups and employed qualitative analysis on a dataset from 13 startups. Through semi-structured interviews, we examine how these companies use data analytics. The findings show that although the benefits from data analytics are clear, multiple barriers and challenges exist for the startups to be able to create value from them. The major ones are about their resources, including human skills, economical resources, as well as time management and privacy issues.
\end{abstract}

Keywords: Startups · Big data $\cdot$ Data analytics $\cdot$ Empirical research

\section{Introduction}

In the digital era of the 21st century information and knowledge becomes readily available to more and more people every day. Societies generate vast amounts of data every moment from multiple sources, transforming them into landscapes mediated by different digital media platforms, digital services, and technologies, leading to the creation of big data and business analytics ecosystems [1]. The different actors of the society (i.e., industry, public and private organizations, entrepreneurs, academia, civil society) are increasingly realizing the potential of the generated data which can lead to value creation, business change, and social change. To this end, many entrepreneurs and startups are actively trying to harness the power of big data and create software and hardware with the 
potential to increase value, gain a competitive advantage, and improve various aspects of human life [2].

Startups are newly created companies producing cutting-edge technology, having a major impact on the global economy [9]. In a context of extreme uncertainty and restricted economical, human, and physical resources, startups have unique challenges related to product development and innovation methods [10]. This results in a high number of failures, primarily due to self-destruction rather than competition [10][11]. Operating in fast-changing, competitive high-risk environments, continuous experimentation is essential for learning and bringing products fast-to-market [12].

There is increasing literature on how big data analytics can generate value towards business or societal transformation [3][4], however further work is needed in order to identify and overcome existing barriers that will allow practitioners to generate value from big data and analytics [5]. Digitization and big data analytics have disrupted business models and can be essential tools to reduce increasing failure rates of established companies [6]. Innovative startups profit on reduced barriers for entering markets with technologies disrupting current distribution channels, customer demands, and customer relationships [7]. Big data analytics plays a crucial role in complementing and even substituting labor for machines, especially in the context of value-creating managerial decisions [8]. Even if the barriers to entry are lowered, startups operate in a context of restricted resources and a lack of technical and managerial skills [13]. However, startups have some characteristics (e.g., ability to quickly change and scale business model) enabling them to compete with mature companies. The role and widespread of data analytics in startups is yet to be explored, even if utilization of such can be a major success factor in the ever-increasing competitive business landscapes [4].

This study focuses on how hardware startups can benefit from big data and seeks to identify the challenges they face which will allow them to make datadriven decisions and generate value from big data analytics. To this end, this paper will offer insight into software and hardware startup companies by answering the following research questions:

RQ1 How can startups create value from (big) data and analytics?

RQ2 What are the barriers for working with (big) data analytics in hardware startups?

To address these questions, this study performs a multiple-case study investigating early-stage European hardware startups, developing products of both hardware and software parts [34]. Even if the potential of (big) data analytics is huge, findings indicate that startups developing both hardware and software do not take advantage of such. To this end, there are identified several challenges and barriers for working with data analytics in such startups, including limited data variety and difficulty of performing business experimentation.

The rest of this paper is organized as follows: Section 2 presents background literature. Section 3 explains our research method, including case selections and data analysis procedure. Section 4 presents the findings from the interviews. Section 5 discusses the results, and highlights directions for future research. 


\section{Background}

\subsection{Product Development in Startups}

The primary objective of startups is to speed up the product development in the early-stages, streamlining the learning process [12]. Startups must respond to fast-changing customer needs and requests [14], both by speeding up the decision and design processes [15]. Startups typically do so by utilizing an evolutionary prototyping approach, meaning that they iteratively refine an initial prototype aiming at quickly validating the product/market fit. Customer feedback highlights new functionality and improvements. As long-term planning is infeasible in the chaotic environment of startups, flexibility and reactiveness are necessary [18].

Instead of utilizing repeatable and controlled processes, startups take advantage of reactive, low-precision engineering practices with focus on the productivity and freedom of their teams [18]. Startups prefer ad-hoc development approaches customized to their own needs, limiting the administrative overhead. In an experimental environment constantly compromising between speed and quality, certain agile practices might not be beneficial (e.g., regular refactoring and test-first), as excessive administrative overhead can inhibit business experimentation [15]. To bring innovative products fast forward, startups depend on team members and resources dedicated to all aspects of the development process, and to be change-oriented and self-initiated. Startups capability to enter new markets and disrupt current business models is largely associated with the uniqueness of human capital and the different approaches they employ.

\subsection{The Importance of Data Analytics}

In the ever-increasing digital world, businesses need to develop and evolve their (big) data analytics capabilities and competencies which are key to achieving successful digital business [4][19]. The evolution of the digital economy and its combination with (big) data analytics is challenging current business models with many startups disrupting well-established companies [20]. Big data refers to expansive collections of data (large volumes) that are updated quickly and frequently (high velocity) and that exhibit a huge range of different formats and content (wide variety) [21]. Yet, there is limited understanding of how entrepreneurs and startups need to change to embrace such technological innovations and generate value in the digital economy. Indeed, they need to build upon their main resources that include people, processes, and technology [22]. This is very important, as it allows businesses and decision-makers to respond almost instantaneously to market needs, thus increasing their operational agility. An iterative and incremental approach combined with frequent releases is essential for startups ability to quickly accommodate frequent change, and adapt prototyping to business strategy [16].

Startups and the individuals working there have the opportunity to take advantage of the available data and create new products transforming a market or 
an industry [3], and big data analytics may be viewed as resources in this process that enable value creation and digital transformation. Many software startups are using existing ecosystems (e.g., Apache Hadoop) to build value-added software and solutions [23]. Nonetheless, since various challenges exist in improving the value creation process, significant research is targeted on addressing these challenges taking into account engineering issues related to specifications, design, or requirements in software development [24]. However, a similar approach is not that easy to be followed by startups that develop both hardware and software. Availability of resources, as well as external and development dependencies, pose restrictions to the implementation of hardware [17], thus influencing the ability of these startups to utilize big data and analytics.

\section{Research Method}

To explore the research questions we performed semi-structured interviews on 13 early-stage European hardware startups. Semi-structured interviews are considered suitable for qualitative data analysis, and allowed for a discoverable approach as interviewees could express themselves more freely and provide their own perspectives on personal experiences related to the research topics [25]. The rest of this chapter presents our research process, including case selections and the collection and analysis of data.

\subsection{Case and Subjects Selection}

The units of analysis are people involved in product development in startup companies that deliver products with mixed hardware and software parts. We defined selection criteria as suggested by Runeson and Höst [26]. Table 1 presents basic information about each case. The current stage in the table is adopted from [27], however the first stage startup is replaced by concept to avoid misunderstandings.

Table 1. Case Descriptions

\begin{tabular}{|l|l|l|l|l|l|}
\hline Case & Product & Current Stage & Founded & Location & \# of employees \\
\hline Startup 1 (S1) & Smart gloves & Concept & 2016 & Norway & 18 \\
\hline Startup 2 (S2) & Medtech biosensor & Concept & 2017 & Norway & 5 \\
\hline Startup 3 (S3) & Physical exercise game & Stabilization & 2016 & Norway & 5 \\
\hline Startup 4 (S4) & Unmanned aircraft system & Concept & 2016 & Norway & 7 \\
\hline Startup 5 (S5) & Advanced noise cancellation & Concept & 2017 & Norway & 5 \\
\hline Startup 6 (S6) & Medtech hydration monitoring & Concept & 2016 & Norway & 10 \\
\hline Startup 7 (S7) & LPG management system & Stabilization & 2016 & Norway & 8 \\
\hline Startup 8 (S8) & Cable cam system & Stabilization & 2016 & Norway & 10 \\
\hline Startup 9 (S9) & Digital piggy bank & Concept & 2017 & Norway & 4 \\
\hline Startup 10 (S10) & Collaborative camera & Growth & 2014 & Norway & 50 \\
\hline Startup 11 (S11) & Interactive children's toy & Concept & 2015 & Netherlands & 8 \\
\hline Startup 12 (S12) & 3D-printer control board & Growth & 2009 & Norway & 1 \\
\hline Startup 13 (S13) & Sensors for IoT & Growth & 2007 & Italy & 25 \\
\hline
\end{tabular}



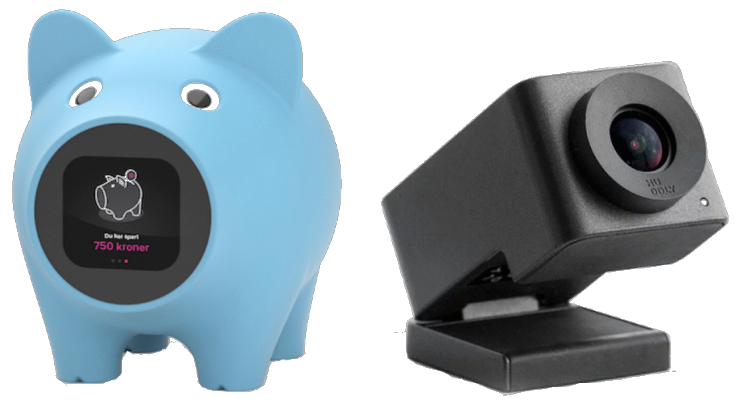

Fig. 1. Product illustration from the investigated startups

Startups were relevant for inclusion in the study if they met the following criteria: (1) The startup develops both hardware and software parts. (2) The startup has been active for at least six months. (3) The startup has a first running prototype. (4) The startup's ambition is to scale its business. People from the relevant startups were eligible for participation if they had experience and/or knowledge about software and/or hardware development. If the candidate met the criteria, he/she was regarded as qualified for contributing to the research study.

We used five different channels to find relevant startups: (1) Innovation Center Gløshaugen, (2) NTNU Accel and FAKTRY, (3) our professional networks, (4) OsloTech and StartupLab, and (5) The Hub. Figure 3.1 presents examples of the products developed by the startups of this study.

\subsection{Data Collection and Analysis Procedure}

Data was collected using a semi-structured interview guideline between February and April 2018. Author one and two attended all interviews to avoid one single interpretation of the respondents' perspectives and insights on topics. This firstdegree data collection approach allowed us to control what data was collected, ensuring that all pre-defined interview questions were answered sufficiently, and exploring new directions by asking follow-up questions [26]. All interviews were recorded and transcribed shortly afterward. Before each interview, we looked into the cases' business background, either through their company websites or other relevant incubator or accelerator websites. Additionally, participants were encouraged to answer a simple questionnaire prior to interviews filling out basic information about themselves and the company. The following list presents the main topics and interview questions of the interview guideline:

- Business background

- Describe your product and team.

- Name the three largest challenges you have encountered.

- Product development 
- What development process do you use?

- How are internal/external factors influencing product development?

- Data analytics

- How do you collect customer data?

- Have you used data analytics for requirements elicitation?

- What are challenges related to data analytics?

The interviews were undertaken in the language preferred by the interviewee (English or Norwegian). Several of the interviews were therefore undertaken in Norwegian as this made the interviewees more comfortable. This allowed them to express themselves more freely, and give more in-depth explanations. Because of this, it was necessary to translate some of the interviews when transcribing. As there often doesn't exist a one-to-one relationship between language and meaning [28], the translation of the transcribed interviews was ensured to "express all aspects of the meaning in a manner that is understandable" [29]. This implies that not all parts of the interviews were directly translated word-for-word.

A total of 68 pages of interview transcripts were analyzed using thematic coding analysis [30]. The transcripts were coded and analyzed using NVivo. Firstly, all authors read through the transcribed interviews to generate initial ideas. Secondly, descriptive coding was applied through an inductive coding approach to systematically identify concepts and topics of interest [32]. Related codes were combined into themes to create patterns and a meaningful whole of the unstructured codes [30]. Section 4 presents the findings from the analysis process.

\subsection{Validity Procedure}

The validity must be addressed for all phases of the case study to enable replication of research [26] and to ensure findings are trustworthy [30]. To ensure validity, we followed guidelines used in controlled empirical experiments in software engineering [33].

Interviewees were either CEOs or engineers with insight into business- and technical-related aspects. As the startups were mostly located in the same area, mainly consisting of young, inexperienced entrepreneurs, generalization is limited to cases with similar characteristics (i.e., early-stage European startups). To decrease the risk of biased interpretations, author one and two attended all interviews. Some interviews were in Norwegian, hence transcripts were not always verbatim to preserve the actual meaning of respondents. Recordings were transcribed shortly after each interview to mitigate bias. Since it is difficult to understand a startup and its dimensions within a time-span of 30 minutes, we collected data about the startups through incubator and company websites prior to interviews. 


\section{Results}

\subsection{Utilization of data analytics}

Among the investigated startups, the usage of data analytics methods was generally limited. Operating in early stages, they were often determined to rapidly develop new features and perform customer validation. The startups in this study mostly relied on qualitative measures (e.g., interviews and observations) to obtain customer feedback. "We have not used data analytics, and do not collect customer data." When focusing on the short-term business goals, they minimized any effort spent on data analytics, rather focusing on the core-delivered values of their products to quickly release a minimum viable product to customers. Improving data collection measures was considered as a rather time-consuming activity. "Data analytics is not something we currently spend time on."

Although the startups commonly spent little time on gathering or learning from data analytics efforts, some had a clear perception of the possible business opportunities and benefits from utilization of such. Even if so, data analytics was usually outside their business scope. "We have looked at some future possibilities of data analytics, but it is not something we currently focus on." A brake-pad in introducing greater focus towards data analytics was that the startups in this study did not have large amounts of data at their disposal. The restricted access to useful data inhibited potential value-adding activities from data analytics. "It's too early for us to get something valuable from data analytics."

The capabilities of team members greatly influence the associated success of startups. From the investigations, we saw an increased focus on data analytics in startups with team members having experience or expertise within the field. Despite for the general limited use of data analytics, possessing the required knowledge and skills of such can have a positive impact on its widespread adoption within a startup organization. "We work with data analytics and do most of it ourselves [...] It requires that your company is able to get that expertise."

Although some of the investigated startups were aware of opportunities and benefits associated with utilizing data analytics for decision-making and requirements elicitation, they mainly focused on the core-delivered functionalities of their products to speed-up development. The findings show, that value-adding activities related to data analytics were considered as less important compared to product development activities.

\subsection{Barriers for obtaining deeper customer insight}

Experimentation, testing, and assessment can be a challenge to startups developing products including both software and hardware components. Physical prototypes are more resource-intensive to develop, in contrast to pure software products, thus limiting startups' ability to test products with a larger customer base. The testing ability of these startups will largely depend on their capacity (i.e., third-party dependency, financial and human resources) to produce prototypes: "There is a great number of people who want to test our product, however, 
we do not have the capacity to produce enough prototypes. The main reason for this is hardware production, which happens in China, and the manual assembly we do ourselves."

Findings from the investigated startups indicate that the amount of collected data in early stages is limited in terms of volume, velocity, and variety, as the data are generated mainly from one prototype used by a couple of users, thus restricting data capture along with their ability to generate value from them. This relates strongly to the early stages of a startup characterized by the existence of only a few customers, as well as to startups developing evolutionary independent systems. Startups may be reluctant to invest in data analytics due to the perceived limitations of the available data: "The data amount is still a little too small to do any proper analysis of it, and we do not collect enough personal info yet to perform the analysis."

Acquiring people with the necessary knowledge and skills in data analytics is one of the major challenges in generating value from (big) data. With startups looking for team members with knowledge in a wide area of fields (boundaryspanning knowledge), it is not easy to put a significant focus on data analytics skills and knowledge. The investigated startups had limited expertise in performing data analytics, and knowledge about available tools suited to address startups' concerns or requirements. The findings show that attracting knowledgeable people is quite hard and with resources being severely restricted, hiring specialized people only to work with data analytics is rarely an opportunity, not to mention a priority of startups: "Finding talented people is hard. Since we are a startup we cannot give very good salary [...] If we had more money we would employ someone to analyze product and customer data [...] I see the value of it, but for the time being, it is not a priority."

The highly competitive environment of startups and severely limited resources imply startups strict priorities. Data analytics efforts may exhaust the already constrained financial and time resources. In addition, collecting the necessary data may present an additional cost of components (e.g., sensors and IoT technology) and human investments. This may be a priority startups are not willing to take: "At the time this [data analytics] is not something we prioritize."

Startups work with innovative technology and products for a wide area of markets. Certain markets may pose specific restrictions and regulations for data collection. This makes the customer testing an intricate process, involving a significant amount of paperwork. Storing customer data for later analyses may be illegal or too entangled, preventing the use of data analytics. Startups need guidelines for handling privacy (e.g., General Data Protection Regulation - GDPR) and security issues to fully take advantage of the benefits of data analytics: "When working with hospitals, data becomes more complicated due to privacy."

The uncertain conditions and fast-changing environment of startups mean long-term planning is not part of their business model, as this is not the way they operate. Some of the investigated startups' business managers lacked the required knowledge to implement data analytics and the potential value in their 
business plan: "I see data analyses as the next step for our business [...] Currently we do not even know what our data can be used for."

\section{Discussion and Conclusions}

This study examines how startups can generate value by employing data analytics methods. With the majority of the literature focusing on startups that create software, here, we choose to investigate startups that develop both hardware and software. This specific category of startups presents great interest due to specific challenges that differentiate them from typical software startups. Indeed these startups are more likely to face challenges such as limited availability of resources or to be dependant on external factors linked with hardware development [17]. Such challenges are expected to affect their ability to use big data and analytics in order to generate value.

The findings show that some of the startups are aware of the potential benefits from using (big) data analytics, however, they face various barriers and challenges which limit them from utilizing them in their business models and business process. Table 2 presents the main barriers to working with (big) data analytics as identified in this study. In detail, the startups face challenges related with their prototyping capacity, as they are able to develop only limited amount of hardware prototypes, thus limiting the number of users that can use them at the same time. This is directly linked with the limited financial resources that young startups have, as well as with the time-shortage that characterizes startups, since they are forced to work on short deadlines and intensive processes.

The challenge with the limited prototyping capacity can indirectly affect data availability. In detail, limited hardware and users lead to an impact to generated data. However, such limitations could be overcome by better planning and more focused testing of their products with their end-users. Furthermore, some of the startups mention that they face specific security and privacy issues related with the use of personal data, due to the nature of their business (e.g., medical technology tested at hospitals). Nonetheless, such barriers can be overcome with the collaboration of the different actors in the society (i.e., industry, government, academia), and the recently directive from EU on data protection (i.e., GDPR) is a step towards that direction. Finally, the startups indicate that generating knowledge from data analytics is not a primary objective for them, thus it is not included in their overall business strategies. This is also linked with the other barriers, regarding prototyping capacity and resource availability, since they believe that they are not able to achieve their short-term goals using data analytics.

Some business managers mention that they possess limited knowledge on what additional value data analytics could provide to their decision-making and design process. Increasing business managers' awareness around the potential knowledge and presenting them with practical information and knowledge will increase the potential of including data analytics in their business models. This can be achieved by offering to startups validated learning, through the use of 
Table 2. Barriers for working with (big) data analytics

\begin{tabular}{|l|l|}
\hline Barrier & Description \\
\hline Prototyping capacity & $\begin{array}{l}\text { Physical prototypes are associated with individual } \\
\text { development costs and time (e.g., third-party dependency). }\end{array}$ \\
\hline Limitations of data & $\begin{array}{l}\text { Data in early startup stages are characterized by low volume, } \\
\text { velocity, and variety. }\end{array}$ \\
\hline Team capabilities & $\begin{array}{l}\text { Startups have high demands for skillful teams with entrepreneurial } \\
\text { capabilities. Experience using data analytics will positively impact } \\
\text { its widespread organizational adoption. }\end{array}$ \\
\hline Timancial resources & $\begin{array}{l}\text { Hardware development includes production, manufacturing, and } \\
\text { logistics, which require more initial human and financial investments. }\end{array}$ \\
\hline Security \& privacy issues & $\begin{array}{l}\text { The uncertain high-risk environment forces startups to release } \\
\text { their products fast and to work under constant pressure. }\end{array}$ \\
\hline Integration with business strategy & $\begin{array}{l}\text { Collecting customer and usage data for (big) data analytics } \\
\text { have associated privacy and security issues. } \\
\text { short-term business goals of startups. }\end{array}$ \\
\hline
\end{tabular}

cohort metrics (e.g., actionable, accessible, and auditable metrics) and analysis. As startups are characterized by short-term planning and frequent releases, utilizing big data analytics will allow startups to make data-driven decisions, which can be faster and with increased quality, thus being consistent with the agile environment that most startups operate.

As with all empirical studies, this study has some limitations. Qualitative data collection measures imply that results and implications are subject to bias. To mitigate the risk of wrong interpretations, author one and two attended all interviews, preferably face-to-face on-site. Recordings were transcribed shortly afterward to preserve respondents' actual meanings. Furthermore, the study would profit from a wider collection of data, both to discover more challenges and to ensure credible conclusions. Also, employing quantitative methods would allow for data triangulation.

This study provides initial knowledge on data analytics in startups, however, future work should investigate more startups both to identify other challenges and barriers, and for generalization of results to a larger startup population (e.g., operating in different markets and lifecycle stages, and various geographical locations). Seeing that the widespread of data analytics is limited, startups need specific methods for utilizing analysis tools in early startup stages. Startup managers need guidance to understand how their data can generate revenues, and what knowledge is required for their organization to thrive from data analytics. Startups need directions for how to implement a data analytics strategy to benefit the company in the long run.

\section{Acknowledgments}

We would like to thank the startups that participated in this study. This project has received funding from the European Unions Horizon 2020 research and innovation programme under the Marie Sklodowska-Curie grant agreement No 751550 . 


\section{References}

1. Pappas, I.O., Jaccheri, L., Mikalef, P., and Giannakos, M.N. (2017) Social Innovation And Social Entrepreneurship Through Big Data: Developing A Reseach Agenda. Presented at the 11th Mediterranean Conference on Information Systems (MCIS), Genoa, Italy.

2. Otero, Carlos E., Peter, Adrian: Research directions for engineering big data analytics software. IEEE Intelligent Systems, vol. 30, pp.13-19. IEEE (2015)

3. George, Gerard., Haas, Martine R., Pentland, Alex: Big data and management. Academy of management Journal, vol.57, pp.321-326. Academy of Management (2014)

4. Mikalef, Patrick., Pappas, Ilias O., Krogstie, John., Giannakos, Michail: Big data analytics capabilities: a systematic literature review and research agenda. Information Systems and e-Business Management, pp.1-32. Springer (2017)

5. Vidgen, Richard., Shaw, Sarah., Grant, David B.: Management challenges in creating value from business analytics. European Journal of Operational Research, vol.261, pp.626-639. Elsevier (2017)

6. Weill, Peter., Woerner, Stephanie L.: Thriving in an increasingly digital ecosystem. MIT Sloan Management Review, vol.56, p.27. Massachusetts Institute of Technology, Cambridge, MA (2015)

7. Lucas Jr, Henry C., Agarwal, Ritu., Clemons, Eric K., El Sawy, Omar A., Weber, Bruce: Impactful Research on Transformational Information Technology: An Opportunity to Inform New Audiences. Mis Quarterly, vol.37 (2013)

8. Loebbecke, Claudia., Picot, Arnold: Reflections on societal and business model transformation arising from digitization and big data analytics: A research agenda. The Journal of Strategic Information Systems, vol.24, pp-149-157. Elsevier (2015)

9. Unterkalmsteiner, M., Abrahamsson, P., Wang, X. F., Anh, N. D., Shah, S., Bajwa, S. S., Baltes, G. H., Conboy, K., Cullina, E., Dennehy, D., Edison, H., FernandezSanchez, C., Garbajosa, J., Gorschek, T., Klotins, E., Hokkanen, L., Kon, F., Lunesu, I., Marchesi, M., Morgan, L., Oivo, M., Selig, C., Seppanen, P., Sweetman, R., Tyrvainen, P., Ungerer, C., Yague, A.: Software Startups - A Research Agenda. E-Informatica Software Engineering Journal, vol.10, pp.89-123. (2016)

10. Giardino, Carmine., Bajwa, Sohaib Shahid., Wang, Xiaofeng., Abrahamsson, Pekka: Key challenges in early-stage software startups. International Conference on Agile Software Development, pp.52-63. Springer (2015)

11. Marmer, Max., Herrmann, Bjoern Lasse., Dogrultan, Ertan., Berman, Ron., Eesley, C., Blank, S.: Startup genome report extra: Premature scaling. Startup Genome, vol.10. (2011)

12. Nguyen-Duc, Anh., Wang, Xiaofeng., Abrahamsson, Pekka: What Influences the Speed of Prototyping? An Empirical Investigation of Twenty Software Startups. International Conference on Agile Software Development, pp.20-36. Springer (2017)

13. Paternoster, N., Giardino, C., Unterkalmsteiner, M., Gorschek, T., Abrahamsson, P.: Software development in startup companies: A systematic mapping study. Information and Software Technology, vol.56, pp.1200-18. (2014)

14. Bosch, Jan: Speed, Data, and Ecosystems: The Future of Software Engineering. IEEE Software, vol.33, pp.82-88. (2016)

15. Pantiuchina, Jevgenija., Mondini, Marco., Khanna, Dron., Wang, Xiaofeng., Abrahamsson, Pekka: Are software startups applying agile practices? The state of the practice from a large survey. 18th International Conference on Agile Software Development, XP 2017, vol.283, pp.167-183. Springer Verlag (2017) 
16. Coleman, G., O'Connor, R. V.: An investigation into software development process formation in software start-ups. Journal of Enterprise Information Management, vol.21, pp.633-648. (2008)

17. Ronkainen, Jussi., Abrahamsson, Pekka: Software development under stringent hardware constraints: Do agile methods have a chance?. International Conference on Extreme Programming and Agile Processes in Software Engineering, pp.73-79. Springer (2003)

18. Berg, V., Birkeland, J., Nguyen-Duc, A., Pappas, I., Jaccheri, L. (2018). Software Startup Engineering: A Systematic Mapping Study. Journal of Systems and Software. doi: 10.1016/j.jss.2018.06.043

19. Pappas, Ilias O., Mikalef, Patrick., Giannakos, Michail N., Krogstie, John., Lekakos, George: Social media and analytics for competitive performance: a conceptual research framework. International Conference on Business Information Systems, pp.209-2018. Springer (2016)

20. Chen, Hsinchun., Chiang, Roger HL., Storey, Veda C: Business intelligence and analytics: from big data to big impact. MIS quarterly, pp.1165-1188. JSTOR (2012)

21. Davis, Charles K.: Beyond data and analysis. Communications of the ACM, vol.57, pp.39-41. ACM (2014)

22. Carlsson, Christer: Decision analytics - Key to digitalisation. Information Sciences. Elsevier (2017)

23. Tan, Wei., Blake, M Brian., Saleh, Iman., Dustdar, Schahram: Social-networksourced big data analytics. IEEE Internet Computing, vol.17, pp.62-69. IEEE (2013)

24. Otero, Carlos E., Peter, Adrian: Research directions for engineering big data analytics software. IEEE Intelligent Systems, vol.30, pp.13-19. IEEE (2015)

25. Oates, Briony J.: Researching information systems and computing. Sage (ISBN: 1446235440) (2005)

26. Runeson, Per., Höst, Martin: Guidelines for conducting and reporting case study research in software engineering. Journal: Empirical software engineering vol.14, p.131. Springer (2009)

27. Crowne, Mark: Why software product startups fail and what to do about it. Evolution of software product development in startup companies. In: Engineering Management Conference, 2002, pp.338-343. IEMC'02. IEEE

28. Temple, Bogusia., Young, Alys: Qualitative research and translation dilemmas. Journal: Qualitative research, vol.4, pp.161-178. Sage Publications London, Thousand Oaks, CA and New Delhi (2004)

29. Larson, Mildred: Translation: theory and practice, tension and interdependence. John Benjamins Publishing (1991)

30. Cruzes, Daniela S., Dyba, Tore: Recommended steps for thematic synthesis in software engineering. Book: Empirical Software Engineering and Measurement (ESEM), 2011 International Symposium on, pp.275-284. IEEE (2011)

31. Wohlin, Claes., Höst, Martin., Henningsson, Kennet: Empirical research methods in software engineering. Book: Empirical methods and studies in software engineering, pp.7-23. Springer (2003)

32. Saldaña, Johnny: The coding manual for qualitative researchers. Sage (2015).

33. Stanfill, R., Astleford, Ted: Improving entrepreneurship team performance through market feasibility analysis, early identification of technical requirements, and intellectual property support. Proceedings of the American Society for Engineering Education Annual Conference \& Exposition (2007)

34. DiResta, R., Forrest, B., Vinyard, R. (2015). The Hardware Startup: Building Your Product, Business, and Brand. " O'Reilly Media, Inc.". 